произведения смысла в тексте про музыку в контексте процесса понимания. Обнаруживаются слагаемые музыковедческой текстологии, анализируются некоторые образцы исследовательского типа музыковедческого текста.

Ключевые слова: текст, смысл, понимание, музыковедение, музыковедческое мышление.

Ionov $V$. The phenomenon of text in musicology: to the problem of immanent objectivity of musicology. The article discusses the ways and means of creating of musicological text. The specific features of the significance reproduction in the text about the music are determined in the context of understanding. The terms of musicological textual criticism is found, some samples of musicological research text are analyzed.

Keywords: text, meaning, understanding, musicology, musicology thinking.

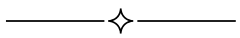

УДК 781.61/781.65

\title{
К. Майденберг-Тодорова
}

\section{ИМПРОВИЗАЦИЯ КАК СРЕДСТВО ИНТЕРПРЕТАЦИИ} АЛЕАТОРНО-СОНОРИСТИЧЕСКОЙ КОМПОЗИЦИИ

Статья посвящена проблеме интерпретирования современной академической музыки. Выявляется общее композиторско-исполнительское свойство алеаторной и сонористической техник, позволяющее объединять случайное и предустановленное в авторском тексте. В связи с этим предлагается различать импровизацию как самостоятельное музыкальное явление и как основной способ интерпретации современного композиторского текста.

Ключевые слова: интерпретация, импровизация, алеаторно-сонористическая композиция, алеаторика, сонористика.

Современная академическая музыка отличается мультиязычностью, синтетичностью выразительных и архитектонических приемов, разнообразием композиторских техник и авторских эстетических позиций. Однако есть ряд показателей, позволяющих привести эти приемы к общему знаменателю. Целью такого обобщения является определение общих смыслообразующих приемов современной музыкальной композиции и возможных способов ее понимания и интерпретирования.

Проблема интерпретации является одной из наиболее традиционных и устойчивых для современного музыкознания. Ее важность и 
актуальность обеспечиваются ее связью с проблемой текста, на что особое внимание обращал Г. Гадамер. В последние годы она приобретает универсальный характер - не только в области науки о музыке, но и в ряду гуманитарных дисциплин философского и психологического профиля, обнаруживая связь, в частности, с проблемой культурного сознания и личностной автономии. Поэтому даже при традиционных подходах проблема интерпретации обнаруживает системную сложность, создает собственные понятийные круги, цепочки эпифеноменов, собственные структурные подразделы.

Значение познавательных канонов по отношению к явлению интерпретации усиливается тем, что в самом этом явлении заложена прочная связь с культурной традицией. Как указывал Г. Гадамер, «в процессе создания произведения художник преодолевает напряжение, возникающее между ожиданиями, идущими от традиции, и новыми привычками, вводимыми им самим. Острота ситуации, переживаемой нами, несомненна, об этом же свидетельствует и своеобразие конфликта и напряженности» [4, с. 274]. Г. Гадамер справедливо замечает, что здесь сходятся две стороны процесса: «наше историческое сознание и склонность современного человека, в том числе и художника, к рефлексии». Это противостояние прошлого и настоящего, традиционного и новаторского и есть процесс интерпретирования. По словам П. Рикера, «всякая интерпретация имеет целью преодолеть расстояние, дистанцию между минувшей культурной эпохой, которой принадлежит текст, и самим интерпретатором. Преодолевая это расстояние, становясь современником текста, интерпретатор может присвоить себе смысл: из чужого он хочет сделать его своим, собственным; следовательно, расширения самопонимания он намеревается достичь через понимание другого» $[10$, c. 48$]$.

Интерпретацию в искусстве следует рассматривать как область герменевтики, поскольку она определяет «аспект понимания, направленного на смысловое содержание текстов» [1]. Любое фиксированное произведение искусства являет собой зашифрованный текст, расшифровка которого находится под влиянием личности того, кто соприкасается с данным текстом. Закладывая определенный смысл в свое произведение, автор не всегда его опубликовывает. Иногда можно найти прямое или косвенное подтверждение толкования в личной переписке, а иногда автор целенаправленно скрывает собственное видение произведения. 
П. Рикер называет интерпретацию работой мышления, «которая состоит в расшифровке смысла, скрывающегося за очевидным смыслом, в выявлении уровней значения, заключенных в буквальном значении» [10, с. 44]. «Работа интерпретации обнаруживает глубокий замысел - преодолеть культурную дистанцию, расстояние, отделяющее читателя от чуждого ему текста, и таким образом включить смысл этого текста в нынешнее понимание, каким обладает читатель» [10, с. 34].

Р. Барт указывает на то, что «произведение есть вещественный фрагмент, занимающий определенную часть книжного пространства (например, в библиотеке)» [3, с. 415]. Интерпретатору приходится работать изначально с текстом. Барт называет текст «полем методологических операций» [3, с. 415]. «Тексту присуща множественность. Это значит, что у него не просто несколько смыслов, но что в нем осуществляется сама множественность смысла как таковая - множественность неустранимая, а не просто допустимая» [3, с. 417]. Г. Гадамер говорит о том, что «единство произведения основывается именно на герменевтической идентичности. Как понимающий я должен идентифицировать. Ибо там было что-то, о чем я рассуждал, что я «понимал». Я отождествляю нечто с тем, что было или есть, и только эта идентичность составляет смысл произведения» [4, с. 291].

Интерпретация - это всегда субъективное явление, так как интерпретирование категорически невозможно без личностного фактора. Способность интерпретировать присуща каждому человеку, в то же время это - отличительная человеческая, индивидуальноличностная, способность. Находим подтверждение в истолковании термина интерпретации В. Демьянковым, который рассматривает интерпретацию как «характеристику художественной презентации, аналогичной музыкальной», которая «обладает субъективностью» [5, c. 40].

Интерпретировать можно как предметы, явления, составляющие обыденную повседневную жизнь, так и факты, события, свершившиеся на определенном историческом расстоянии, а также - возможные в будущем. Объекты искусства являются событием, находящимся во всех временных положениях - в прошлом, настоящем и будущем. Если интерпретация повседневных явлений может быть связана в данный момент времени только лишь с одной личностью, то интерпретирование объектов искусства всегда подразумевает наличие, как минимум, двух сторон интерпретации по отношению к 
этому одному объекту. Первая сторона интерпретации - это автор, вторая - реципиент. Такое сочетание сторон возможно по отношению к произведениям литературного или художественно-изобразительного видов искусства. В сфере музыкального творчества интерпретация предстает еще более сложным и многогранным явлением, связанным с тремя субъективными позициями, обусловленными обязательными условиями сушествования музыкального произведения - триадой композитор - исполнитель - слушатель.

В современной академической композиторской практике, в условиях раскрепощения авторского композиторского текста исполнителю предоставлена значительная свобода в проявлении индивидуального начала, влияющего не только на целостность произведения, но и на детали, составляющие музыкальное целое, а следовательно, на форму и содержание целого. Композитор не является исполнителем, но сознательно возлагает часть своих функций на «второе лицо», то есть на исполнителя, который вынужден частично решать композиторские задачи. При этом композитор нередко руководствуется возможностями исполнителя, что определяет спектр выразительных музыкальных средств.

Анализ современной музыкальной партитуры выявляет ряд параметров, предоставляющих возможность раскрепощения авторского текста, объединяющих многие композиторские концепции. Такими параметрами являются:

- мобильность формы, мобильность звуковысотного материала, мобильность ритмического рисунка;

- временна́я и графическая фиксация нотного текста, фреймовая (паттерновая) запись одного или нескольких компонентов музыкальной ткани или формы;

- ярко выраженные приемы алеаторического или сонористического письма;

- наличие авторских предписаний относительно применения исполнительской импровизации в композиторском тексте;

- «незвучащие структуры» [2], несущие драматургическую и смысловую нагрузку, визуально обозначенные в нотном тексте;

- усиленная роль приемов исполнения, звукоизвлечения, то есть артикулирования.

Перечисленные параметры музыкальной ткани современной композиции обнаруживаются на пересечении алеаторного и сонористического типов композиторского мышления в их полном или ча- 
стичном проявлении в музыкальном материале. Таким образом, формируется особый тип алеаторно-сонористической композиции как тип современной композиторской поэтики, выступающий в оппозиции к академически-традиционному музыкальному произведению.

Алеаторно-сонористическая композиция предстает перед нами как особая открытая форма текста, характеризующаяся разомкнутостью структурной организации и свободной множественностью семантических составляющих текста, дающая исполнителю значительную личностную интерпретативную свободу. Проявление данной свободы реализуется посредством импровизирования исполнителем на заданные, условно фиксированные, текстовые значения.

Импровизацией пронизаны все уровни современного музыкального произведения. Она присутствует даже тогда, когда визуально не обозначена в партитуре. Авторский замысел подразумевает свободное отношение исполнителя к интонационности, ритмической, фактурной стороне, что неизбежно влечет за собой индивидуальнонеповторимое раскрытие замысла произведения. Тесно переплетаясь воедино, композиционно-выразительные приемы алеаторики и сонористики становятся не только способом общего движения или развивающего построения, но и образуют тематические элементы, которые влекут за собой иные принципы вариантного развития, содержащие импровизационное начало.

Искусство импровизации лежит в основе как полной, так и ограниченной алеаторики, находится на всех ее структурных уровнях звуковысотном, ритмическом, метрическом, хронометрическом, темповом, динамическом. Являясь исторически первичной по отношению к алеаторике, импровизация, как музыкальное явление, неоднократно вырабатывала устойчивый комплекс выразительных средств, направленных на сиюминутное, одномоментное музыкальное выражение, как в донотную эпоху, так и во времена устоявшейся традиции нотной фиксации. «Всякая импровизационная культура строится на фонде текстов, хорошо известных не только музыкантам, но даже слушателям. Таким фондом в западноевропейском средневековье были григорианские песнопения; в эпоху Реформации, барокко и классицизма во многих странах - протестантский хорал; в джазе - разные типы блюза и темы-«стандарты», в качестве которых выступают мелодии популярных шлягеров 20-30-х годов; в индийской музыке - совокупность раг; в арабской, персидско-азербайджанской и среднеазиатской музыке - макамы, мугамы, макомы. 
Обучение импровизации обычно начинается с заучивания на память этого общего фонда текстов» [7, с. 35].

Импровизация первична по отношению к фиксированному тексту. Необходимость в нотной записи возникает благодаря стремлению установить единичный вариант импровизируемого материала. Алеаторика, как композиторская техника и как способ «нефиксированной» нотной записи, - по отношению к фиксированному тексту - вторична, так как возникла в результате стремления отойти от рамок нотной записи, сковывающей композиторское мышление.

Ранними предпосылками к современному способу записи алеаторики нам представляется практика произвольной замены вокальных голосов инструментальными в средневековой и ренессансной европейской музыке, способ записи XVII-XVIII веков, при котором гармония не выписывалась в отдельных голосах, а обозначалась цифрованным басом, традиция импровизационной сольной каденции в классических инструментальных концертах, а также различные музыкальные шутки, игры, основанные на случайности. Задатки алеаторики прослеживаются и в мелизмах и в связанных с ними особенностями нотной записи, если не указывается скорость чередования украшающих нот. Разумеется, приведенные примеры касаются относительного или управляемого типа алеаторики. Говоря о первом типе алеаторики, абсолютном, стоит задуматься, возможна ли вообще абсолютная алеаторика - как абсолютная случайность в полном значении этого словосочетания. Описывая классификацию алеаторики, Ц. Когоутек отделяет алеаторику творческого процесса от алеаторики исполнительского и репродуктивного процесса. Как нам представляется, тип абсолютной алеаторики возможен только для первого, творческого процесса, в котором для сочинения музыки использованы сопутствующие материалы - игральные кости, монеты, пятна на листе бумаги, становящиеся своеобразной «программой» для «случайного» сочинения музыки. Переходя в стадию записанного текста, такая музыка превращается во второй тип алеаторики - ограниченный. Если такая музыка не предается нотной записи, то она становится просто импровизационным процессом. Тип авторской абсолютной алеаторики не является всецело «случайным», поскольку он находится в рамках выбора материала, служащего опорой для создания подобного произведения. Композитор, выбирая для себя игральные кости, монеты или другие «подручные» средства, сам предустанавливает каноны, ограничения, в которых затем творит «случайную» музыку. 
Импровизация - как явление чисто художественное - подчиняется принципам рационализации, продуманности. Алеаторика подчиняется своим первичным законам - законам случайности. Но тут следует уточнить, что, говоря о случайности, мы подразумеваем абсолютную, чистую алеаторику - до того момента, как она становится фиксированным произведением. Лишь на этой фазе возможно «случайное регулирование» сочетаний, комбинаций. Лишь в тот период времени, когда происходит сам процесс образования случайности, проявляется «связь с жизнью» посредством непредсказуемости звуковысотных образований, их непредвиденности, которая лежит в основе эстетической концепции импровизации. Но все это возможно в «донотный период» произведения. Становясь оформленным на бумаге (каким бы то ни было способом), оно переходит из разряда «случайного» в разряд «художественного», где уже вступает в свои полномочия импровизация как художественно-композиционное явление.

Основное различие импровизации и алеаторики заложено в их первичной природе. Импровизация - это явление преимущественно устного характера, алеаторика - явление всецело письменной традиции. Импровизация - самостоятельное и самодостаточное явление, алеаторика без импровизации невозможна.

Если говорить о звуковых качествах алеаторики, то в качестве их основообразующего элемента часто выступают сонористические приемы. На наличие точек соприкосновения алеаторики и музыки тембров указывает Ц. Когоутек [6, с. 246], отмечая роль такого соединения в создании алеаторным способом звуко-красочного построения. Также на точки взаимопроникновения алеаторной и сонористической техник указывает С. Путилова, раскрывая стилистические параметры некоторых произведений В. Лютославского. С. Путилова указывает на сонорные качества алеаторной техники в симфонической поэме «Пространство сна» как на один из организующих принципов сонористической фактуры, называет его «алеаторическим контрапунктом» $[9$, с. 10], а также именует сонористический метод Лютославского «алеаторическим типом соноризма», [9, с. 10].

Если говорить о сонористическом типе изложения композиторской мысли, то импровизация становится неизбежным определением пространства свободы исполнителя, реализуя временной план звуковой материи - распределение расстояния от звука к звуку. В таких произведениях на первый план выходят средства выразительности, находящиеся в палитре, прежде всего, исполнительской - агогика, 
артикуляция, динамика. Именно они играют первостепенную роль в импровизационном процессе, позволяют импровизатору-исполнителю быть непредсказуемым, таким образом формируют, расширяют область допустимых трактовок авторского текста до бесконечности. Когда временной отрезок не обозначен ни паузами, ни даже промежутком, измеряемым секундами, а просто расстоянием на бумаге, то расстояние во времени становится пространством импровизации.

Сонористическая запись во многих отношениях является мнемонической (напоминающей то, что уже существовало в памяти). Она ближе к типу устной нотации, с чем и связан не до конца устоявшийся характер сонористических знаков, их различные начертания и толкования различными композиторами. Поэтому она находит себя как новую форму музыкальной речи, освобожденную от высотно-ритмической закрепленности.

Таким образом, в современной партитуре формируются алеаторно-сонористические комплексы, заключающие в себе неразрывность алеаторного метода композиции и сонористического воплощения звукового материала. Их исполнение осуществляется средствами исполнительской импровизации, которая, в свою очередь, выступает как неотъемлемый и необходимый план современного композиторского творчества, особенно выразительный в условиях алеаторно-сонористической организации произведения.

Поэтому мы предлагаем находить в импровизации два различных направления музыкально-исполнительской практики: импровизацию как самостоятельный творческий акт сочинения музыки в ее устной форме без опоры на фиксированный текст, в основе которого лежит оперирование мнемоническими музыкально-смысловыми блоками; импровизацию как основной способ исполнительской интерпретации открытого текста, выступающий в роли коммуникативного материала между исполнителем и композитором, использующий в качестве организующего начала фиксированные элементы и связи в структуре композиторского текста. В традиционном понимании импровизация предстает как способ сочинения музыки в ее устной форме без опоры на фиксированный текст. В музыке второй половины XX - начала XXI века импровизация становится структурным принципом композиции, обеспечивающим свободу выбора исполнителя, то есть становится частью системы записи произведения, приобретая парадоксальные черты. Когда импровизация, то есть свободное сочинение текста с возможностью замены одной части другой, осуществляется 
на основе записанных указаний исполнителю, то она тем самым приобретает парадоксальность, поскольку исходит из письменного материала и становится обязательной, направляемой, регулируемой.

Проявление импровизации в различных музыкальных сферах как самостоятельной (автономной) музыкальной формы и как способа композиторско-исполнительского выразительного средства при сочинении и исполнении современных музыкальных произведений - позволяет признавать ее средством коммуникации между исполнителем и слушателем в случае с устным текстом и между композитором и исполнителем в случае с открытым текстом, а также основным способом интерпретирования открытого текста.

Современное композиторское мышление уже само по себе является интерпретативным по отношению к устоявшимся жанровым и эстетическим критериям музыкальной выразительности. Нередко ракурс интерпретации меняется от произведения к произведению, тем самым открывая новые возможности понимания хронотопических показателей музыки. Особенностью интерпретативного характера алеаторно-сонористической композиции является то, что она вынуждает заново создавать музыкальную семантику, каждый раз заново организовывать пространство и время звучания в качестве музыкального. Семантическая сторона алеаторно-сонористической композиции проявляется, прежде всего, в отношении композитора к собственному тексту, в интерпретировании им жанров, форм, в отношении к тематическому материалу. Главным параметром, который объединяет все тенденции алеаторно-сонористической композиции - это семантика открытости, свободы, которая понимается нами как «непредсказуемая неслучайность», то есть фактор случайного, становящийся закономерным явлением алеаторно-сонористической композиции.

Как необходимая сторона музыкально-творческого процесса импровизация входит в текстовую структуру и алеаторной, и сонористической технологии, следовательно, является необходимой и для композиторской интерпретации произведения. Поскольку импровизация является средством и результатом творческой деятельности человека, она способна нести доступную информацию и влиять на эстетическое сознание личности, следовательно, является важной художественной составляющей композиций с открытым текстом, помогает раскрыть семантику алеаторно-сонористической композиции. 


\section{СПИСОК ЛИТЕРАТУРЫ}

1. Азаренко С. Интерпретация [Электронный ресурс] / С. Азаренко // Философская энциклопедия / [ред.-сост. В. Кемеров]. - М. : Панпринт, 1998. - Режим доступа : http://terme.ru/dictionary/183/word/interpretacija

2. Аркадьев М. Креативное время, «археписьмо» и опыт Ничто [Электронный ресурс] / М. Аркадьев. - Режим доступа : http://philosophy.ru/ library/arcad/kreatime.html - Название с экрана.

3. Барт Р. От произведения к тексту / Р. Барт // Р. Барт Избранные работы: Семиотика. Поэтика. - М. : Прогресс, Универс, 1994. - С. 413-423.

4. Гадамер Г. Актуальность прекрасного / Г. Гадамер. - М. : Искусство, 1991. - C. 266-323.

5. Демьянков В. Интерпретация, понимание и лингвистические аспекты их моделирования на ЭВМ / В. Демьянков. - М. : Издательство Московского университета, 1989. - $172 \mathrm{c}$.

6. Когоутек Ц. Техника композиции в музыке XX века / Ц. Когоутек ; [пер. с чешск. К. Н. Иванов ; общ. ред. и коммент. Ю. Н. Рагс и Ю. Н. Холопов]. - М. : Музыка, 1976. - 367 с.

7. Мальцев С. О психологии музыкальной импровизации / С. Мальцев. М. : Музыка, 1991. -88 с.

8. Путилова С. Соноризм как художественное явление в музыке польських композиторов 60-70-х годов XX века : автореф. дис. ... канд. искусств. : спец. 17.00.02 «Музыкальное искусство» / Светлана Михайловна Путилова. - М., 2011. -25 c.

9. Путилова С. Соноризм как художественное явление в польской музыке второй половины XX века [Электронный ресурс] / С. Путилова // ГЛОБЭКСИ : интернет-журнал Академии труда и социальных отношений. - M. : АТиСО, 2009. - Режим доступа: http://www.globecsi.ru/Articles/2008/Putilova. pdf

10. Рикер П. Конфликт интерпретаций. Очерки о герменевтике / П. Рикер ; [пер. с фр. И. Вдовина]. - М. : КАНОН-пресс-Ц; Кучково поле, 2002. $624 \mathrm{c}$.

Майденберг-Тодорова К. Імпровізація як засіб інтерпретації алеаторно-сонористичної композиції. Стаття присвячена проблемі інтерпретування сучасної академічної музики. Виявляється спільна композиторсько-виконавська властивість алеаторної та сонористичної технік, що дозволяє поєднувати випадкове та предвстановлене в авторському тексті. У зв'язку з цим пропонується розрізняти імпровізацію як самостійне музичне явище та як основний засіб інтерпретування сучасного композиторського тексту.

Ключові слова: інтерпретація, імпровізація, алеаторно-сонористична композиція, алеаторика, сонористика. 
Maidenberg-Todorova K.. Improvization as means of interpretation of aleatoric-sonoristic composition. The article is dedicated to problem of interpretation of contemporary academic music. The common composer and performing property of aleatoric and sonoristic techniques, what let to combine the random and preestablished in authors text is reveals. In this connection it is proposed to distinguish improvisation as the independent musical phenomenon and as the basic way of interpretation of the contemporary composer text.

Keywords: interpretation, improvisation, aleatoric-sonoristic composition, aleatoric, sonorism.

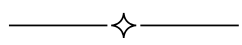

УДК 008:001

\section{О. Яковлев}

\section{СИНЕРГІЯ КУЛЬТУРНИХ ІДЕНТИЧНОСТЕЙ РЕГІОНІВ УКРАЇНИ}

У статті подана проблема використання теорії синергетики у культурологічних дослідженнях. Представлена стратегія синергії культурних ідентичностей регіонів України з досвіду науково-дослідної діяльності Національної академії керівних кадрів культури і мистецтв, співпраці з Одеською національною академією імені А. В. Нежданової.

Ключові слова: культурні ідентичності, регіони України, синергія, коеволюція, культурний континуум України, гуманітарні стратегії, модель культурного простору.

У сучасній науці синергетика стала визнаним міждисциплінарним напрямком досліджень, присвячених вивченню складних систем, компоненти яких взаємодіють між собою нелінійним чином. На сьогоднішній день парадигма самоорганізації найбільш широко використовується в природничих науках і техніці, але іiі основні принципи та ідеї поступово проникають у соціально-гуманітарні науки. Подальшого розвитку потребують синергетичні напрацювання на двох рівнях: загальнометодологічному і конкретно-дослідницькому, зокрема культурологічному.

Г. Хакен, І. Пригожин, С. Курдюмов, які започаткували дослідження теорії синергії, підкреслювали, що основні закономірності самоорганізації, виявлені при вивченні природних термодинамічних процесів, мають широкий спектр дії, охоплюючи розвиток соціокультурних систем. Цей напрямок знайшов підтвердження в

(с) Яковлев О., 2014 